\title{
Benefits of urban light rail trains: a perspective from Spain
}

\author{
S. Carpintero ${ }^{1}$, V. Maraña ${ }^{2} \&$ R. Barcham ${ }^{3}$ \\ ${ }^{1}$ Polytechnic University of Madrid, Spain \\ ${ }^{2}$ Scott Wilson Business Consultancy, UK \\ ${ }^{3}$ Norbridge Inc., USA
}

\begin{abstract}
Environmental issues are currently at the forefront of transport policies within the urban, regional and international contexts. Different modes of transport, and the alternative means of their regulation, have a significant impact on the levels of pollution and on reserves of natural resources, as well as on the health and quality of life of individuals. In this context, light rail transit systems have thrived in cities all over the world as an alternative to fossil fuelled private and public options. In particular, in Spain, sixteen (16) projects have been implemented by Local and Regional Authorities from 1992 to 2009 with the goal of improving mobility while meeting environmental challenges. Additionally, a number of other Authorities are at the moment considering similar projects, and numerous feasibility analyses are being performed.

In its first part this paper compiles information on various light rail projects mentioned above, including technical, commercial and procurement aspects, and highlights the innovative PPP schemes employed in some of them. Second, the paper addresses the main benefits of these experiences in comparison with traditional transport systems. These benefits include reduction of carbon emissions; energy savings; economic efficiencies; improvements in mobility, punctuality, quality of life and accessibility; and the redesign and integration of urban space. Final conclusions are drawn, along with a discussion of prospects for the short and medium term.
\end{abstract}

Keywords: light rail, environment, BOT, concession, PPP, Madrid. 


\section{Introduction}

Environmental issues represent a growing concern in the development of urban policies. The direct effects of transport on environmental pollution are of particular relevance. In particular, traffic congestion has a considerable negative impact on the environment, on the health of urban populations and on overall quality of life. Furthermore, traffic is one of the principal sources of atmospheric pollutants such as ozone and $\mathrm{NO}_{2}$, and is also the source of approximately 40 percent of total transport-related $\mathrm{CO}_{2}$ emissions. In addition, nearly two-thirds of injury-causing traffic accidents in the European Union occur in urban areas. Finally, noise pollution in urban areas, of which an estimated 80 percent is caused by traffic, also constitutes an area of growing concern.

Despite the undoubted advantages of urban transport for economic and social development, it is essential that urban transport policies be compliant with the new environmental and community legislation and standards. In this context, the construction of light rail systems in various Spanish cities represents a step change towards the implementation of sustainable transport alternatives. This paper analyses these experiences and reviews the environmental benefits of light rail systems.

\section{Recent development of light rail systems in Spain}

\subsection{Introduction}

The last several years have witnessed the construction and commissioning of numerous light rail systems in several Spanish urban areas. The first light rail system was delivered into service in Valencia in 1992. Between then and 2009, fifteen (15) additional light rail systems have been built, comprising a total of $294 \mathrm{~km}$; the total initial capital expenditure amounts to Eur2007 3.0bn (see Table 1).

This section analyses the economic and technical aspects of some of these projects. The study focuses on seven projects for which it has been possible to obtain detailed and reliable information, namely: Arganda del Rey (Madrid), Boadilla (Madrid), Parla (Madrid), Pozuelo (Madrid), Tenerife (Canary Islands), Trambaix (Barcelona) and TramBessos (Barcelona). Additionally, in order to provide an international benchmark, some of the key data for these projects are compared to those obtained for four European projects; these include Lyon (France), Croydon (United Kingdom), Sheffield (United Kingdom) and Oporto (Portugal).

\subsection{Operating data}

Operating data depicted in Table 2 show an average speed of some 20 kilometres per hour for the Spanish projects, in line with the European experiences also shown in the table. However, it is worth mentioning that in terms of traffic Spanish light rails carry approximately half of the passengers of the other European light rail lines examined, and also travel approximately half of the vehicle-km (see Table 2). 

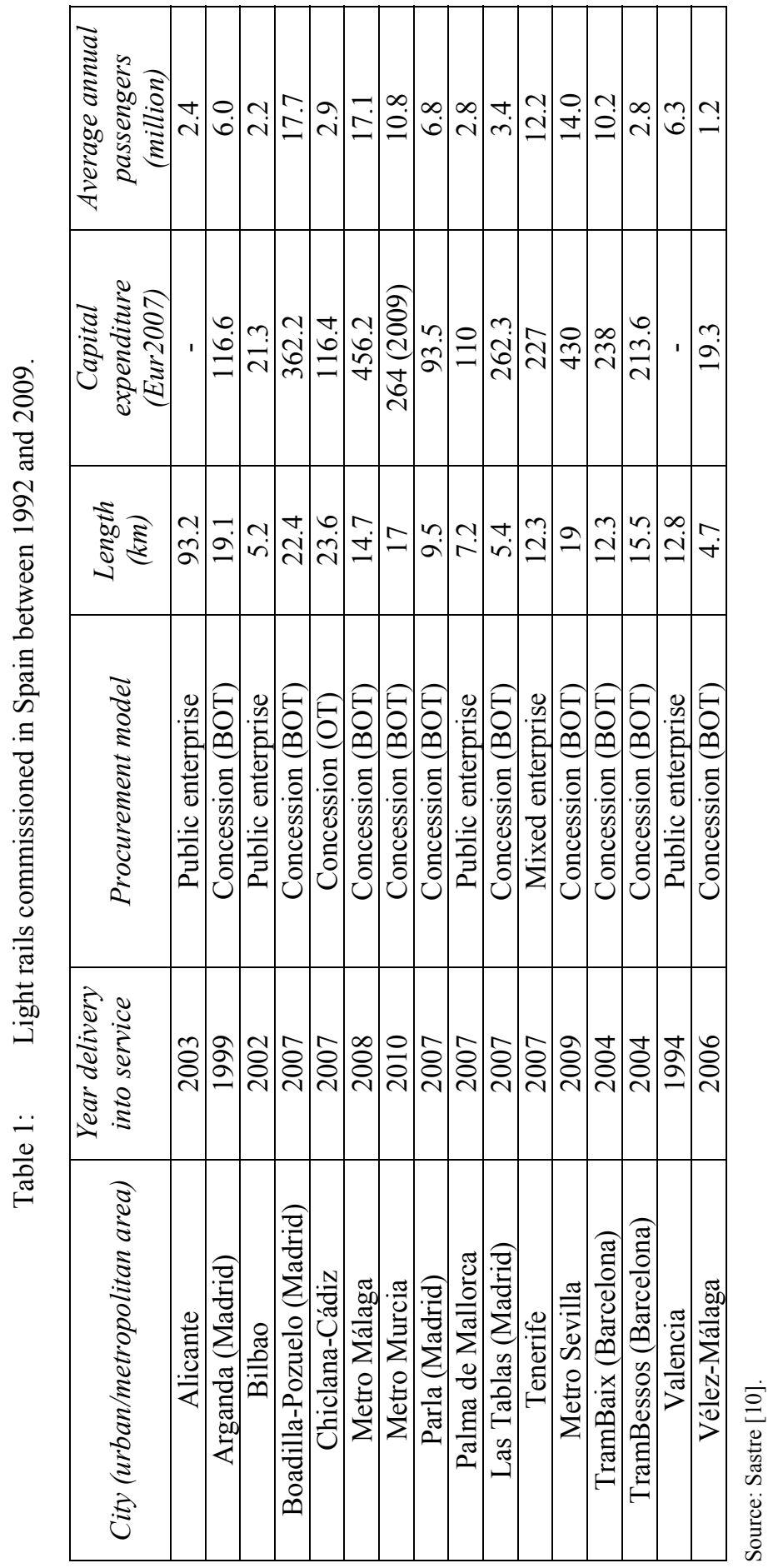
Table 2: $\quad$ Technical data relating to operations (2007).

\begin{tabular}{|c|c|c|c|}
\hline Project & $\begin{array}{c}\text { Commercial } \\
\text { speed }(\mathrm{km} / \mathrm{h})\end{array}$ & $\begin{array}{c}\text { Veh.- } \\
\mathrm{km}(\mathrm{k})\end{array}$ & $\begin{array}{c}\text { Pass. } \\
(\mathrm{k})\end{array}$ \\
\hline Arganda (Mad.) & 49,6 & 1,224 & 6,013 \\
\hline Boadilla (Mad.) & 24,7 & 1,204 & 7,984 \\
\hline Parla (Mad.) & - & - & - \\
\hline Pozuelo (Mad.) & 23,4 & 876 & 9,876 \\
\hline Tenerife (Canary I.) & - & - & - \\
\hline Trambaix (Bcn.) & 18 & 1,200 & 10,186 \\
\hline TramBessos (Bcn.) & 19 & 446 & 2,811 \\
\hline Lyon (France) & 16,7 & 2,511 & 33,704 \\
\hline Croydon (UK) & 21,5 & 2,500 & 22,500 \\
\hline Sheffield (UK) & 21,4 & 2,500 & 12,800 \\
\hline Oporto (Portugal) & 25,7 & 2,455 & 14,908 \\
\hline
\end{tabular}

Source: Sastre [10].

\subsection{Analysis of capital expenditure (Capex) and operational expenditure (Opex)}

Analysis of Capex and Opex for the set of Spanish projects selected reveals that the average cost per kilometre of light rail in Spain falls within the range of Eur2009 10m-20m, as shown in Table 3. These figures are comparable to other

Table 3: $\quad$ Capex and Opex data.

\begin{tabular}{|c|c|c|c|c|c|}
\hline Project & $\begin{array}{c}\text { Cost/km } \\
(M €)\end{array}$ & $\begin{array}{c}\% \\
\text { under- } \\
\text { ground }\end{array}$ & $\begin{array}{c}\text { Annual } \\
\text { cost/pass } \\
(€)\end{array}$ & $\begin{array}{c}\text { Tech. } \\
\text { fee } \\
(€)\end{array}$ & $\begin{array}{c}\text { Opex per } \\
\text { annum } \\
(\text { M })\end{array}$ \\
\hline Arganda (Mad.) & 5.93 & 0 & 18.88 & 1.79 & - \\
\hline Boadilla (Mad.) & 15.33 & 90 & 26.58 & 4.53 & 8 \\
\hline Parla (Mad.) & 9.84 & 0 & 13.75 & 0.9 & 6 \\
\hline Pozuelo (Mad.) & 17.47 & 65 & 15.51 & 4.53 & 9.8 \\
\hline Tenerife (Canary I.) & 18.40 & 0 & 18.61 & - & 9 \\
\hline Trambaix (Bcn.) & 18.76 & 2 & 22.63 & - & - \\
\hline TramBessos (Bcn.) & 13.23 & 0 & 73.21 & - & - \\
\hline Lyon (France) & 20.37 & 0 & 14.69 & - & - \\
\hline Croydon (UK) & 10.75 & 0 & 13.07 & - & - \\
\hline Sheffield (UK) & 17.70 & 0 & 27.66 & - & 11.1 \\
\hline Oporto (Portugal) & 40.22 & 13 & 159.26 & - & - \\
\hline Average & $\mathbf{1 7 . 0 9}$ & - & $\mathbf{3 6 . 7 1}$ & - & $\mathbf{1 3}$ \\
\hline
\end{tabular}

Source: Sastre [10]. 
European experiences as depicted in the same table, with the exception of Oporto. Using the latest available passenger data (from 2007), a calculation of annual cost per passenger shows average figures in the range of 15 to 25 Euros, once more comparable to values from foreign projects, again excluding Oporto.

Operating and maintenance costs are between 8 and 10 Euros2009 per kilometre, and technical fees fall between 1 and 4.5 Euros. It has not been possible to obtain the value of the technical fees for foreign projects, precluding comparison on this measure.

\subsection{Procurement alternatives}

Out of the sixteen (16) light rails commissioned in this period only four (4) have been procured through traditional procurement routes, while the rest have been procured through different formulas of collaboration between the private and public sectors. The most common formula has been the Concession, which is granted in most of the cases for Build-Operate-Transfer - BOT - schemes, but can also be granted only for the operation of an existing infrastructure. In one of the instances the project has been implemented through a mixed Special Purpose Company with private and public shareholders.

The following section describes in detail all the commercial and financial aspects of the procurement mechanisms used by the Madrid Regional Government for the implementation of recent light rail projects.

\section{Private involvement in financing and operation of light rail systems: projects in the Madrid region}

The light rail projects built in Madrid in recent years offer an interesting example for the analysis of the mechanisms of private participation in the procurement and funding of this type of infrastructure. This section highlights some of the key aspects of the procurement of the following projects:

- Light rail to Boadilla del Monte

- Light rail to Pozuelo de Alarcón

- Light rail to Sanchinarro and Las Tablas

- Parla Tramway

The Madrid Regional Government arranged the construction of the three initial lines through the traditional public procurement rout. Work commenced in 2005 upon award of contracts by the public entity Mintra (Madrid Infraestructuras del Transporte). Under this original arrangement, Mintra would have eventually granted the relevant concessions for the operation of the light rail lines.

Mintra, established in 1999 by the Madrid Regional Government, is a public entity whose main role is the management and implementation of infrastructure projects within the Madrid region. Mintra's tasks include, among others:

- budget programming;

- development of feasibility studies, preliminary and final designs;

- land and right-of-way purchase; 
- $\quad$ procurement of construction works;

- $\quad$ supervision of works;

- maintenance of existing infrastructures; and,

- $\quad$ purchase of new rolling stock

However, shortly after, Eurostat determined that Mintra should be considered a public company under the European Accountancy System. In light of this decision, all of Mintra's projects would have to be consolidated with the Regional Government's public debt, for public accounting purposes. Instead, the Regional Authorities reacted to Eurostat's unexpected decision by modifying the initial procurement arrangement in order to obtain the removal of the projects from the balance sheet.

A key goal for the Regional Government in this process was the minimisation of eventual delays in the commissioning of the new tram lines. Therefore the Authorities swiftly developed a new contractual arrangement which entailed a new risk transfer profile for the deal and which also took into consideration the construction contracts already in place. As early termination of these contracts would have resulted in delays in the whole programme schedule, the Regional Government held negotiations with all contractors, succeeding in obtaining subrogation of all the original contracts, with the Concessionaire replacing Mintra as contractual party.

Under the new contractual arrangement, the new tram lines were procured through concession schemes granted by Mintra including the construction, operation and maintenance of the lines. The scheme also required the provision of new rolling stock. This was supplied by Mintra to the respective concessionaires, whose obligations included its purchase and maintenance. Finally, the procurement of a new depot was also included under the concession for the T1 line.

The total duration of the contracts were set at 30 years. During this period the concessionaire would receive payments from the grantor based on actual demand; the payments would also be subject to performance adjustments. However, revenue risk was capped at $+/-30$ percent of anticipated demand. The fare per passenger paid by the concession grantor and the cap of the revenue risk were subject to bid by the contenders at the tender stage.

In the case of the Parla Tramway, on the other hand, two key issues are to be highlighted in relation to its procurement:

- Firstly, 75 percent of the initial CAPEX was funded through real estate capital gains stemming from significant residential developments in the project's area of influence. This is the only light rail project in Spain financed in such manner Indeed there are very few similar cases around the world; which include Copenhagen's automated metro, Hong Kong's public transport network, the Docklands Light Rail, and several recent cases in Japan.

- Secondly, during the first five years revenue is based on capacity of the line, i.e. vehicle-kilometres available; however, upon expiry of the initial 5-year period the concessionaire will be bearing traffic risk. This arrangement takes recognition of the fact that transport demand for the 
Parla system relies largely on future urban developments which may be accelerated as a consequence of the implementation of a sound public transport network.

\section{Environmental upsides of light rail systems}

Concern over the environmental effects of urban transport occupies a prominent place in the global environmental agenda. Ever greater emphasis is placed on the effort to achieve a transport networks that are efficient and offer sustainable mobility and that are compatible broader social and community aims.

The past decades have produced a continuous growth in the number of vehicles circulating on the highways and roads of developed countries. This has in turn instigated numerous studies on the environmental consequences of transport, with particular focus on the increasing carbon emissions and other gases and pollutants, and their noxious effect on human health. Until recently, the principal policy instrument for regulating environmental impacts of transport has been the imposition of vehicle emissions standards achieved through technological improvement. Nonetheless, it has become clear that these methods are no longer sufficient if the environmental goals of the international community, such as the targets set by the Kyoto Protocol, are to be achieved.

Environmental issues represent one of the most important upsides of light rail systems. Therefore, having discussed the rapid evolution of this means of transport in Spain, it is important to highlight the principal environmental benefits expected:

- A more efficient use of natural resources. Unlike other modes of transport such as the automobile or the bus, light rail is driven by electric power. Therefore use of limited resources and emissions of pollutants can be reduced by use of renewable sources for electricity generation.

- The absence of polluting emissions since light rail vehicles does not contain fossil-fuelled combustion engines. In addition to this, light rail may lead to overall reduction in the overall emission of greenhouse gases by capturing traffic from other means of traffic (one light rail train is equivalent to three or four buses).

- Energy savings deriving from the generation of electric power by the braking system that can be reused within the system.

- The reduction of noise pollution. Light rail systems operating at maximum speed generate noise at around 60 decibels, far below the daytime noise levels in congested high-density urban areas. Furthermore, the design and materials used in the rails, along with the anti-vibration systems fitted in the rail cars, contribute significantly to the reduction in noise generated by system operations.

Beyond strictly environmental benefits, light rail systems further contribute to a higher urban quality of life. The following features of light rail systems are relevant in this respect: 
- Light rail vehicles are often pleasant, comfortable and versatile, and employ the latest technology, with low floors that considerably facilitate accessibility for all passengers.

- Light rail as a mode extends the right to transport to all citizens and allows an equitable division of public space, often strongly dominated by the automobile.

- Transit along dedicated tracks allows light rail to circulate at attractive commercial speeds, meeting scheduled timetables and thus, providing a reliable service to the users.

- Road occupancy is reduced, allowing more driving and parking space for remaining vehicles. As a result, there is a potential for urban space becoming more comfortable and accessible for pedestrian mobility.

- Light rail contribute to consolidate the urban pattern, limiting the distance of transit movements and favouring the creation of a compact, mixed-use city, with integration of residential, professional, academic, commercial and leisure areas.

\section{Concluding remarks}

The recent history of public and private investment in urban light rail systems in Spain underlines the clear wager by many Spanish Local and Regional Governments for this means of transport, which offers important advantages in comfort, safety, reliability, and time savings. Altogether, twelve (12) Spanish cities have inaugurated a total of sixteen (16) projects, most of them during the last decade. Other than the experiences in Madrid and Barcelona, Spain's two largest cities, the light rail systems have been implemented in medium sized cities, with populations ranging between 300,000 and 800,000 inhabitants. Two (2) projects have been procured in cities of less than 150,000 inhabitants, which are however part of Greater Madrid's metropolitan area.

This paper has analysed some of the key parameters related to Capital and Operational expenditure in these projects, and has provided an international benchmark based on similar rail systems implemented in other European cities. The analysis suggests that light rail projects in Spain present analogous characteristics to similar projects around Europe.

The majority of light rail systems entering into operation in Spain since 2000 have been procured through formulas that require private funding, the DBOT concession formula being the most common. This has been concurrent with the development and implementation of public-private partnerships in a broader spectrum of transport infrastructures in Spain. Spanish contractors and investors have gained international relevance and, indeed, the publication Public Works Financing ranked in late 2009 seven Spanish firms in the top ten (10) league of infrastructure concessionaires.

The use of concessions formulas for light rail projects in Spain has been fundamentally driven by the aim of optimising public and private resources for infrastructure investment. In the case of in the case of the Madrid light rail, the use of the BOT formula encountered some legal obstacles, which were 
successfully overcome. In other projects, such as the Parla Tramway, the concession grantor has introduced innovative funding and revenue arrangements based on the use of real estate capital gains.

It should be noted that nine of the fifteen projects completed in Spain have only entered into revenue service within the last three years. This suggests that it may still be early for conclusive analysis of these experiences. Such further study may constitute a stimulating subject for future research.

This paper has furthermore explored the principal environmental advantages offered by light rail systems and its contribution to further improvements in urban quality of life. These can be summarized as:

- Reduction of greenhouse gas emissions;

- Improvement of urban air quality;

- Reduction of traffic-generated noise pollution;

- Increased energy efficiency in urban transport;

- Decrease in urban congestion;

- Improvement in the quality of the urban environment;

- Reduction of footprint;

- Reduction in waste products generated by urban transport; and

- More sustainable use of natural resources.

\section{References}

[1] Cascajo, R. (2006) Efectos sobre la movilidad de metros y tranvías, I.T., n. 76.

[2] CE (2004) Comunicación de la Comisión de 11 de febrero de 2004 "Hacia unas estrategia temática sobre el medio ambiente urbano" COM (2004) 60

[3] Novales, M.; Orro, A. y Rodríguez Bugarín M. (2002) Aplicaciones europeas del tren-tranvía, una nueva orientación del transporte público ferroviario, Revista de Obras Públicas, n. 3.424

[4] EEA Report (2004) Ten key transport and environment issues for policymakers. European Environment Agency Report n. 3/2004

[5] EEA Report (2006) Transport and environment: facing a dilemma. European Environment Agency Report n. 3/2006

[6] Harmatuck, D. (2008), Light rail cost functions and technical inefficiency, Transportation Research Record: Journal of the Transportation Research Board, n. 2042, 58-70.

[7] Litman, T. (2007) Evaluating rail transit benefits: A comment, Transport Policy, 14, 94-97

[8] Ministerio de Medio Ambiente (2005) Informe sobre Transporte y Medio Ambiente, TRAMA 2005, Dirección General de Calidad y Evaluación Ambiental y TRANSYT.

[9] Ordoñez, J. (2002) Las aportaciones ambientales de los tranvías. Via libre, n. 453, mayo. 
[10] Sastre, J. (2009) Nuevas concesiones de metro ligero: Participación pública y privada. Comparación de modelos de financiación y gestión, Doctoral Thesis, School of Civil Engineering, Polytechnic University of Madrid.

[11] Stokes, R.; Macdonald, J. and Ridgeway, G. (2008) estimating the effects of light rail transit on health care costs, Health \& Place, 14, 45-58.

[12] Winston, C. and Maheshri, V. (2007) On the social desirability of urban rail transit systems, Journal of Urban Economics, 62, 362-382.

[13] Zamorano, C.; Bigas, J. and Sastre, J. (2008) Tranvías, metros ligeros y sistemas de plataforma reservada. Puntos clave para su proyecto e implantación, Revista de Obras Públicas, n. 3.487. 